\title{
Statistical Assessment of Simplified CPTU-Based Hydraulic Conductivity Curves
}

\author{
Mingfei Zhang $\mathbb{D}^{1}$ and Liyuan Tong $\mathbb{D}^{2}$ \\ ${ }^{1}$ Civil Engineering and Architecture Institute, Zhengzhou University of Aeronautics, Zhengzhou, Henan, China 450046 \\ ${ }^{2}$ Institute of Geotechnical Engineering, Southeast University, Nanjing, Jiangsu, China 210096 \\ Correspondence should be addressed to Liyuan Tong; 101010519@seu.edu.cn
}

Received 20 November 2020; Revised 28 December 2020; Accepted 26 January 2021; Published 26 February 2021

Academic Editor: Bin Gong

Copyright (c) 2021 Mingfei Zhang and Liyuan Tong. This is an open access article distributed under the Creative Commons Attribution License, which permits unrestricted use, distribution, and reproduction in any medium, provided the original work is properly cited.

\begin{abstract}
Classical theoretical approaches to evaluate CPTU-based hydraulic conductivity gave the expression of a bilinear relation defined by $K_{D}-B_{q} Q_{t}$, for undrained and drained soils. In fact, a dividing line may be selected with a certain degree of subjectivity, and several undrained/drained points occur in opposite sites, which may make us doubt the necessity of two intersecting lines to distinguish the undrained and drained soils. And a uniform and relatively simple curve including an arc, parabola, or ellipse correlation may be more suitable and accessible from a practical point of view. A database in the Yangtze Delta region has been collated to assess the three curves compared with the bilinear line. With the graphical and statistical analyses, the results indicate that the arc, parabola, and ellipse simplified curves could give better performance than the bilinear line. Through the statistical analyses and the number of variables, the overall best curve was the ellipse with only two variables, which is expected to improve the application scope and simplicity of hydraulic conductivity.
\end{abstract}

\section{Introduction}

Empirical correlations become significant to estimate soil parameters during construction projects, especially due to the lack of test equipment or cost, limited time for testing, etc. [1-4]. In this perspective, there are some attempts available to obtain in situ hydraulic conductivity for engineering application. As a labor-saving and cost-effective approach, gradually, instead of a conventional test, the piezocone penetration test (CPTU) has been employed widely in geotechnical engineering to determine the mechanical properties of the soil, including the hydraulic conductivity [5-9]. The methodology to assess hydraulic conductivity of soils from piezocone soundings can be divided into three major categories, the dissipation test method [10,11], the soil behavior index method [6], and theoretical analysis method, wherein the last one has explicit equations to interpret the penetration process based on Darcy's law and the cavity expansion theory [12-18]. In this method, Chai et al.'s method [16] modified from
Elsworth and Lee's method $[14,15]$ can be regarded as the classical and well-known approach in terms of a bilinear line defined by $K_{D}-B_{q} Q_{t}$, for undrained/drained soils. Yet, it increases difficulties in distinguishing different soils. And the large variability of the intersection point also hinders the accuracy, simplicity, and operability of the piecewise functions. In addition, a dividing line may be selected with a certain degree of subjectivity [17], and the points in undrained and drained soils may be located in the adverse zone, which may lead us to doubt the necessity of two intersecting lines to distinguish the undrained and drained soils.

Hitherto, an attempt for a uniform and relatively simple curve can be more suitable and accessible from a utilitarian point of view. Herein, three types of uniform curves, arc, parabola, and ellipse, are proposed to estimate $B_{q} Q_{t}$ from piezocone soundings in USA, Japan, and China more universally and precisely. And then, these three curves are compared with a classical bilinear line using statistical methodology. 


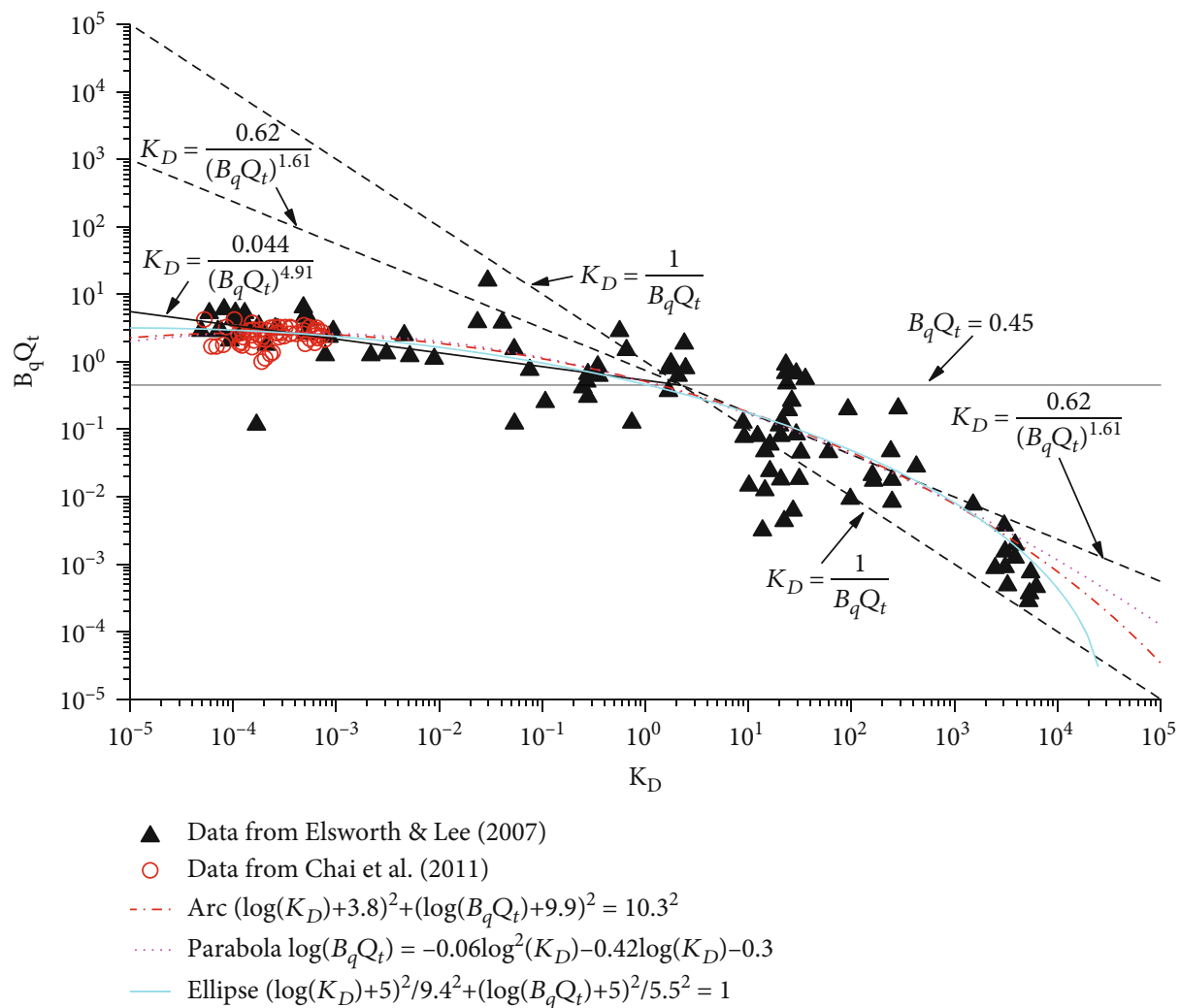

Figure 1: Relationship between measured nondimensional hydraulic conductivity $K_{D}$ and $B_{q} Q_{t}$ from piezocone test (data from Chai et al. (2011)).

\section{Methodology}

2.1. Classical Theoretical Method. Based on numerous CPTU data and practice, Elsworth and Lee [14] proposed an explicit method (short for Elsworth's method) to calculate the hydraulic conductivity from the piezocone sounding records:

$$
K_{D}=\frac{4 k \sigma^{\prime}{ }_{\nu 0}}{a \gamma_{w} U},
$$

or

$$
k=\frac{\gamma_{w} K_{D} U}{4 k \sigma_{v 0}^{\prime}},
$$

in which, $B_{q}$ and $Q_{t}$ are defined as [19]

$$
\begin{aligned}
& B_{q}=\frac{u_{2}-u_{0}}{q_{t}-\sigma_{v 0}}, \\
& Q_{t}=\frac{q_{t}-\sigma_{v 0}}{\sigma_{v 0}^{\prime}} .
\end{aligned}
$$

Then, Elsworth and Lee $[14,15]$ suggested a more reasonable correction using curve fitting adjustment:

$$
K_{D}=\frac{0.62}{\left(B_{q} Q_{t}\right)^{1.6}}
$$

In place of a spherical surface flow of pore water, assuming a half-spherical surface flow covers the tip of the cone, Chai et al. [16] presented a classical modified approach (short for Chai's method), in terms of a bilinear relation (see Figure 1):

$$
K_{D}^{\prime}=\left\{\begin{array}{l}
\frac{1}{B_{q} Q_{t}}, \quad B_{q} Q_{t}<0.45 \\
\frac{0.044}{\left(B_{q} Q_{t}\right)^{4.91}}, \quad B_{q} Q_{t}>0.45
\end{array}\right.
$$

2.2. Empirical Expressions. From observation of the piezocone penetration test results from Elsworth and Lee [15] and Chai et al. [16] (see Figure 1), it is proposed that the dividing line is $B_{q} Q_{t}=0.45$, which coincides with Equation (11) presented by Chai et al. [16]. The dotted line $K_{D}=0.62 /\left(B_{q} Q_{t}\right)^{1.61}$ and solid line $K_{D}=0.044 /\left(B_{q} Q_{t}\right)^{4.91}$ are from Elsworth's method [14] and Chai's method [16], respectively, and the dotted line $K_{D}=1 / B_{q} Q_{t}$ pertains to Elsworth's method and Chai's method that are in forms of bilinear correction. It is obvious that Chai's method [16] agrees with the scatter points better than Elsworth's method; however, the dividing line $B_{q} Q_{t}=$ 0.45 which distinguished the undrained and drained soils seems to be factitious and fluctuant. If this argument is accepted, a uniform curve that neglects the different soils and is less complicated can provide an accurate and simple correlation. Hence, the fitting curves of the arc, parabola, 


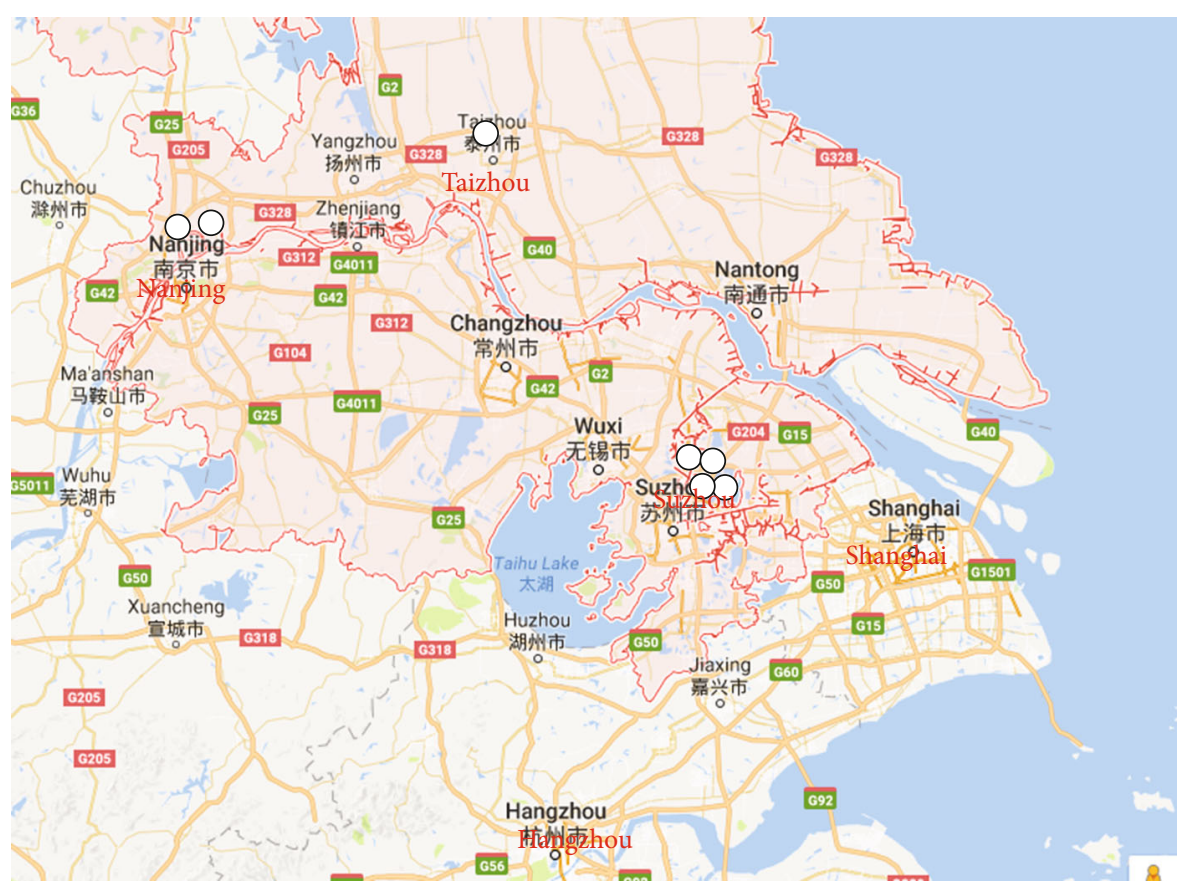

Figure 2: Map of the CPTU sites.

TABLE 1: Soil properties and description of sites.

\begin{tabular}{|c|c|c|c|c|c|}
\hline Site name & Major soil layer & Depth range $(\mathrm{m})$ & Site name & Major soil layer & Depth range $(\mathrm{m})$ \\
\hline \multirow{3}{*}{ Yushan station (Suzhou) } & Clay & $1.0 \sim 4.8$ & \multirow{3}{*}{$\begin{array}{l}\text { Xinghui road station } \\
\text { (Suzhou) }\end{array}$} & Clay & $2.0 \sim 11.8$ \\
\hline & Clay-rich silt & $5.5 \sim 7.0$ & & Silty sand & $12.0 \sim 18.5$ \\
\hline & Silty clay & $18.6 \sim 22.4$ & & Silty clay & $19.5 \sim 28.6$ \\
\hline \multirow{3}{*}{ Hongzhuang station (Suzhou) } & Clay & $0.8 \sim 3.8$ & \multirow{3}{*}{$\begin{array}{c}\text { Zhuhui road station } \\
\text { (Suzhou) }\end{array}$} & Clay & $1.7 \sim 4.9$ \\
\hline & Silty clay & $5.5 \sim 13.6$ & & Silt & $11.0 \sim 16.8$ \\
\hline & $\begin{array}{l}\text { Silty sand-rich } \\
\text { silty clay }\end{array}$ & $21.2 \sim 28.0$ & & Silty clay & $16 \sim 22.6$ \\
\hline \multirow{3}{*}{ Jiangbei work well (Nanjing) } & Silty clay & 2.3 & \multirow{3}{*}{$\begin{array}{l}\text { The fourth Yangtze } \\
\text { river bridge (Nanjing) }\end{array}$} & Silty clay & $1.2 \sim 4.1$ \\
\hline & Muddy clay & $8 \sim 10$ & & Silty sand & $6.2 \sim 9.8$ \\
\hline & Clay & $16 \sim 18$ & & Silty sand & $16.5 \sim 18.4$ \\
\hline \multirow{3}{*}{ The Yangtze bridge at Taizhou (Taizhou) } & Muddy clay & $0.8 \sim 1.8$ & & & \\
\hline & Silty clay & $3.1 \sim 13.4$ & & & \\
\hline & Silty sand & $18.1 \sim 28.6$ & & & \\
\hline
\end{tabular}

and ellipse are presented in terms of dash-dotted line, dotted line, and heavy solid line shown in Figure 1. Through curve fitting, the "best-fit" expressions for the arc, parabola, and ellipse to the data collected by Elsworth and Lee [15] are given by

$$
\begin{gathered}
\left(\log \left(K_{D}\right)+3.8\right)^{2}+\left(\log \left(B_{q} Q_{t}\right)+9.9\right)^{2}=10.3^{2} \\
\log \left(B_{q} Q_{t}\right)=0.06 \log ^{2}\left(K_{D}\right)-0.42 \log \left(K_{D}\right)-0.3 \\
\frac{\left(\log \left(K_{D}\right)+5\right)^{2}}{9.4^{2}}+\frac{\left(\log \left(B_{q} Q_{t}\right)+5\right)^{2}}{5.5^{2}}=1 .
\end{gathered}
$$

The three curves seem complex in terms of logarithm, yet they are simple in the process because the $x$-axis and $y$-axis are also on double logarithmic scales. It is noted that there are three, three, and two variables in Equations (6) through (8), separately, for the reason that the factor of 5 in Equation (8) is constant which may be derived from the logarithm of the minimum of $x$-axis and $y$-axis. Owing to concentration of the data from [16], all four curves conform well to the data, which are represented as rings in Figure 1.

\section{Data}

A collection data of seven sites in the Yangtze Delta that lie on the eastern part of China is shown in 

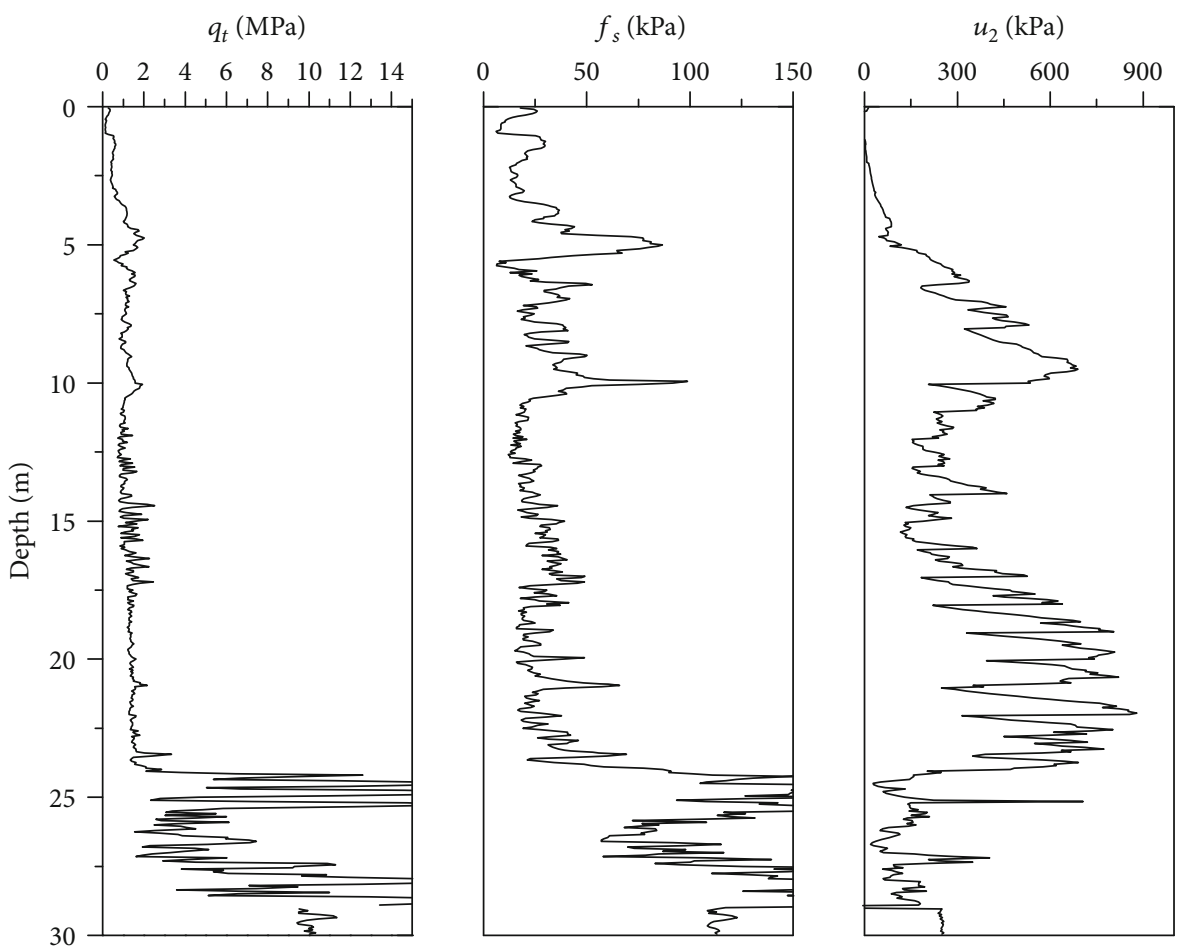

FIgURE 3: Typical CPTU soundings recorded at Hongzhuang station, Suzhou.

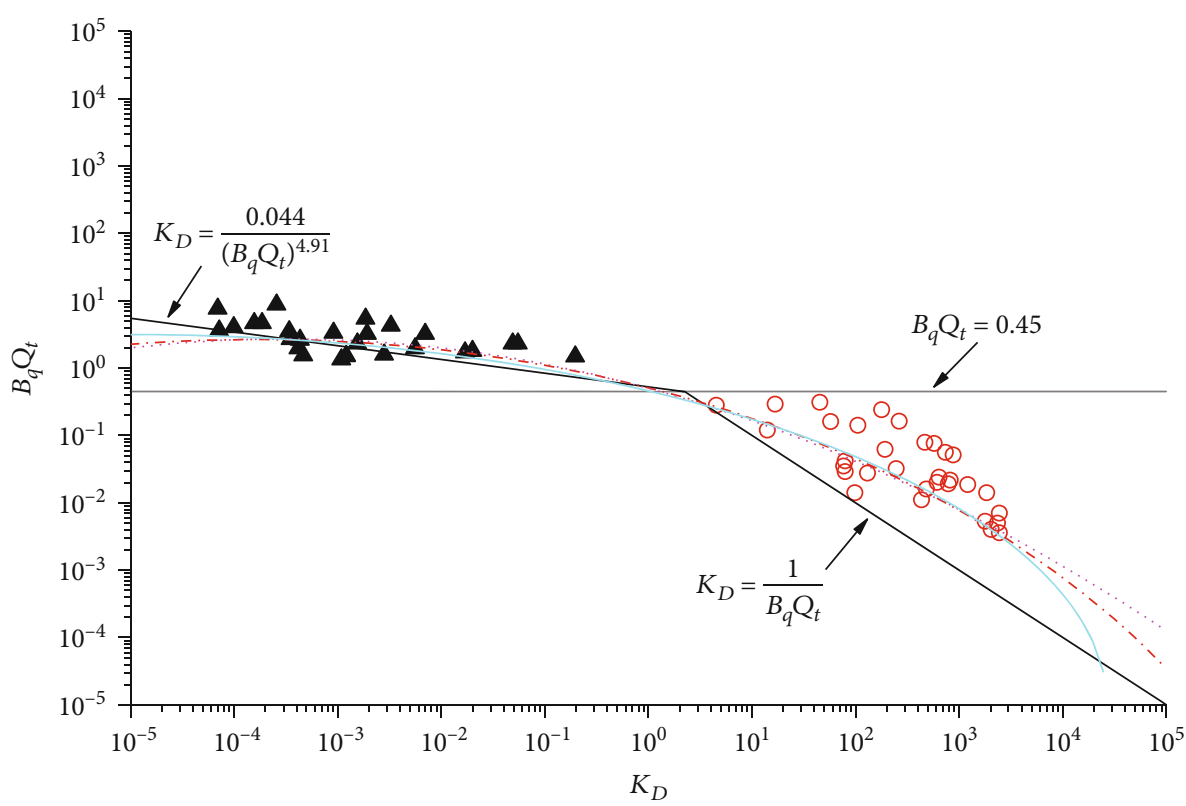

- Clay under undrained condition

- Soil under partially drained condition

-. . $\operatorname{Arc}\left(\log \left(K_{D}\right)+3.8\right)^{2}+\left(\log \left(B_{q} Q_{t}\right)+9.9\right)^{2}=10.3$ Parabola $\log \left(B_{q} Q_{t}\right)=-0.06 \log ^{2}\left(K_{D}\right)-0.42 \log \left(K_{D}\right)-0.3$ Ellipse $\left(\log \left(K_{D}\right)+5\right)^{2} / 9.4^{2}+\left(\log \left(B_{q} Q_{t}\right)+5\right)^{2} / 5.5^{2}=1$

FIGURE 4: Relationship between measured nondimensional hydraulic conductivity $K_{D}$ and $B_{q} Q_{t}$ (data from this paper).

Figure 2. A summary description of soils in these sites is presented in Table 1. Typical profiles of CPTU measurements, including cone tip resistance $\left(q_{t}\right)$, side friction resis- tance $\left(f_{s}\right)$, and pore water pressure $\left(u_{2}\right)$ versus depth recorded at Hongzhuang station in Suzhou, are indicated in Figure 3. 


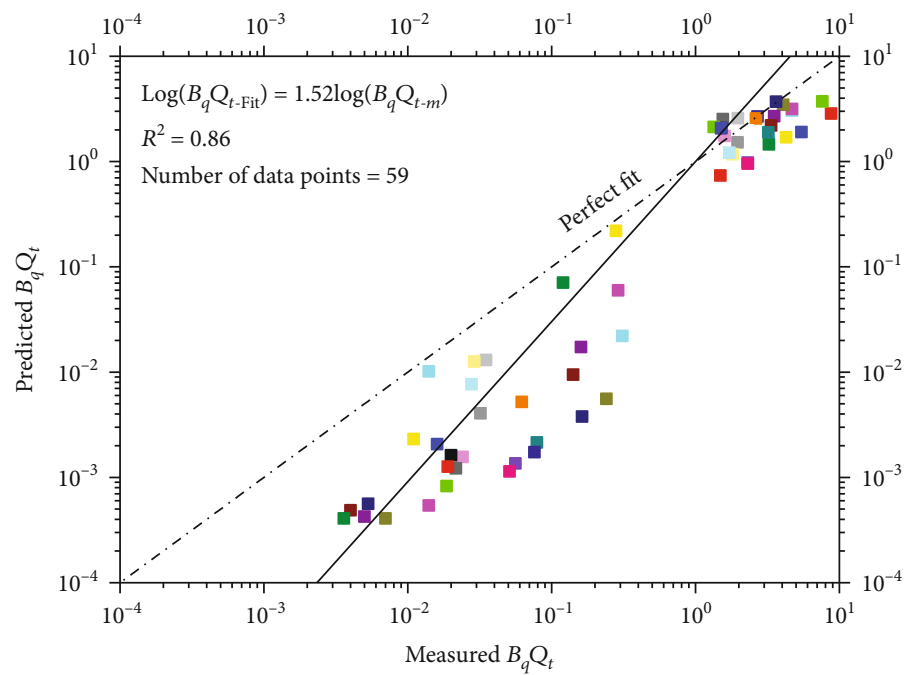

(a)

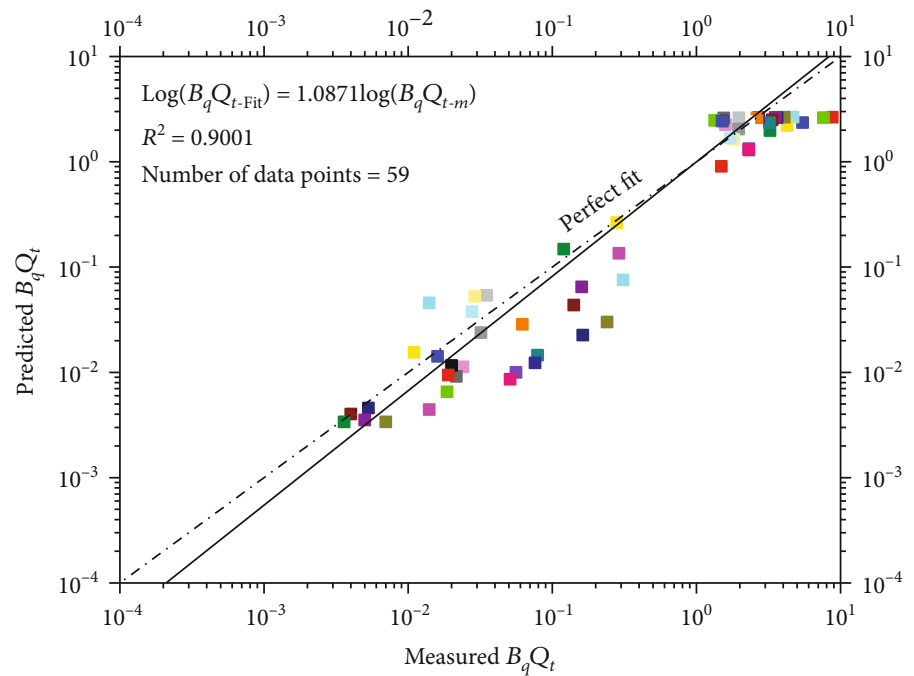

(b)

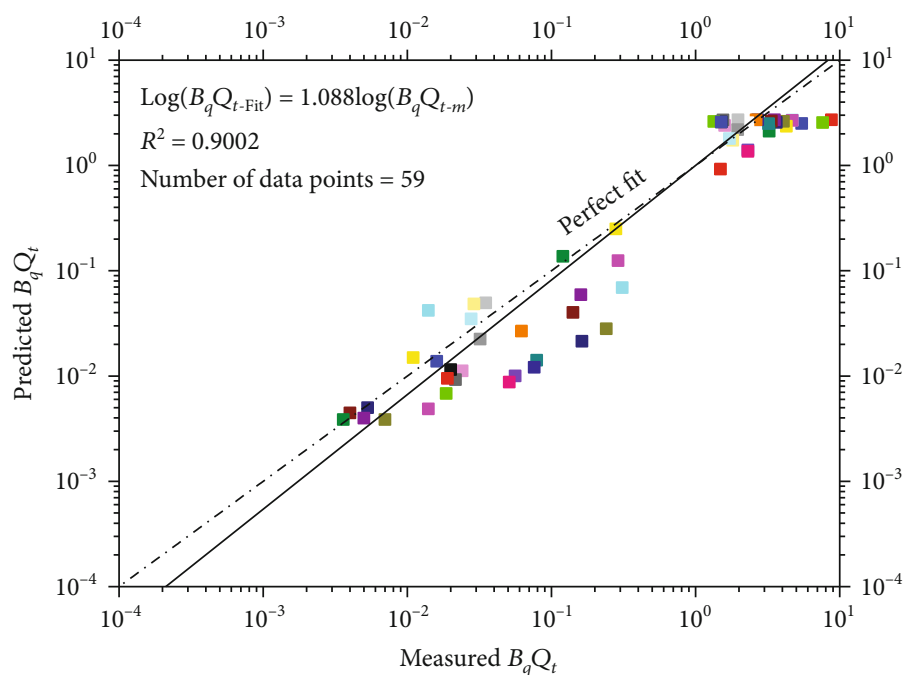

(c)

FIgURe 5: Continued. 


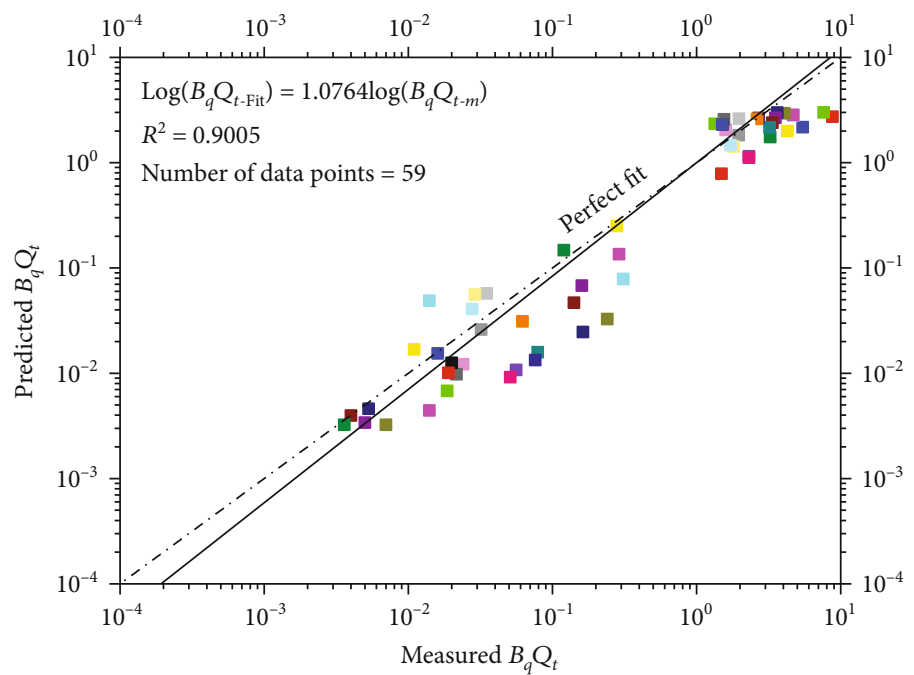

(d)

FIGURE 5: Measured versus predicted $B_{q} Q_{t}$ values for different curves: (a) bilinear, (b) arc, (c) parabola, and (d) ellipse (data from this paper, China).

The applied CPTU device is produced by VertekHogentogler \& Co. of USA. The equipment is a versatile piezocone system fabricated with $60^{\circ}$-tapered, $10 \mathrm{~cm}^{2}$ tip area cone which provided measurements of $q_{t}, f_{s}$, and $u_{2}$ with a $5 \mathrm{~mm}$ thick porous filter located just behind the cone tip. The penetration rate in this study was $20 \mathrm{~mm} / \mathrm{s}$.

\section{Analysis}

4.1. Qualitative Analysis. For the data proposed in this paper, four curves are revealed in Figure 4 . Figure 4 shows that the bilinear correction gives worse performance, while the others make slight difference obviously.

4.2. Quantitative Analysis. There is little doubt that qualitative analysis provides a visualized way to compare these curves; however, this does not give quantitative accuracy. Hence, five measures of effectivity (MOEs) are used to further assess the validity of the abovementioned curves. RMSE is the square root of the average of the squared, which is given as

$$
\mathrm{RMSE}=\sqrt{\frac{1}{n} \sum_{i=1}^{n}\left(B_{\mathrm{c}}-B_{\mathrm{m}}\right)^{2}} .
$$

The ratio $K$ of the estimated $B_{q} Q_{t}$ to measured $B_{q} Q_{t}$ can be defined by

$$
K=\frac{B_{c}}{B_{m}}
$$

The ranking index (RI) proposed by Briaud and Tucker [20] and the ranking distance (RD) proposed by
Cherubini and Giasi [21] are other methods of expressing an overall judgment, which are expressed as

$$
\mathrm{RI}=\left|\mu_{\ln (K)}\right|+\sigma_{\ln (K)},
$$

$$
\mathrm{RD}=\sqrt{\left(1-\mu_{K}\right)^{2}+\sigma_{K}^{2}}
$$

For correlation equations where the precision, indicated by the standard deviation and mean value, and the accuracy are similar, $\mathrm{RD}$ gives a better result than RI, while for those that are either very accurate or very precise, RI gives the best result $[2,4]$. RD has been used by numerous investigators $[2,4,22-24]$ to evaluate the performance of empirical equations.

Relative error (RE) [23-32] is the proportion of the absolute difference between the measured and the estimated to the measured hydraulic conductivity, which is given as

$$
\mathrm{RE}=\frac{\left|B_{c}-B_{m}\right|}{B_{m}}
$$

The lower the RMSE, RE, RI, and RD values are, the better the performance the curve gives.

Figure 5 and Table 2 reveal that the bilinear line proposed a worst correlation with the determination coefficient $\left(R^{2}\right)$ value of 0.86 between the measured and predicted $B_{q} Q_{t}$ values, whereas the ellipse curve gave the best performance $\left(R^{2}=0.9005\right)$. 
TABLE 2: Results of the RMSE, $K, \mathrm{RE}, \mathrm{RI}$, and RD (data from the present paper, China).

\begin{tabular}{|c|c|c|c|c|c|c|c|c|c|}
\hline Curve & RMSE & $>1(\%)$ & $\begin{array}{l}K \\
|\mu|\end{array}$ & $\sigma$ & $>0(\%)$ & $\begin{array}{l}\mathrm{RE} \\
|\mu|\end{array}$ & $\sigma$ & RI & $\mathrm{RD}$ \\
\hline The bilinear & 1.234 & 0.119 & 0.463 & 0.432 & 0.119 & -0.537 & 0.305 & 2.692 & 0.689 \\
\hline Arc & 1.330 & 0.153 & 0.656 & 0.469 & 0.153 & -0.344 & 0.288 & 1.507 & 0.581 \\
\hline Parabola & 1.342 & 0.186 & 0.656 & 0.474 & 0.186 & -0.344 & 0.282 & 1.559 & 0.586 \\
\hline Ellipse & 1.327 & 0.203 & 0.667 & 0.475 & 0.203 & -0.333 & 0.290 & 1.408 & 0.580 \\
\hline
\end{tabular}

\section{Discussion}

A summary of the results of the RMSE, $K, \mathrm{RE}, \mathrm{RI}$, and RD analyses for soil data from this paper is revealed in Table 2. Regarding RMSE, the bilinear curve (RMSE =1.234) gave the best prediction unexpectedly. For the general overestimation $(K>1$ or $\mathrm{RE}>0)$ of $B_{q} Q_{t}$, all four curves had below $50 \%$ of the $K$ values greater than 1 . In terms of accuracy, the ellipse curve, proposed in this paper, with two variables gave the most accurate evaluation of $B_{q} Q_{t}$, with a mean $K$ of 0.667 , yet the bilinear curve gave the worst performance with a mean $K$ of 0.463 . In terms of precision determined by SD of $K$, the bilinear curve gave the most precise prediction with a mean SD of 0.432 . Yet, in terms of precision determined by $\mathrm{SD}$ of RE, the parabola curve gave the most precise prediction with a mean SD of 0.282 . With respect to RI, the best performance was delivered by the arc curve proposed in this study $(\mathrm{RI}=1.408)$. In terms of $\mathrm{RD}$, the most efficient curve was the ellipse curve $(\mathrm{RD}=0.580)$ proposed in this paper. In these MOEs, RD is a better parameter for comparing the suitability of the different curves [2]. In addition, only the ellipse curve involves two variables; the other curves use three variables. Hence, the overall best curve was the ellipse $(\mathrm{RD}=0.580)$.

\section{Conclusions}

The existing classical bilinear relation defined by $K_{D}-B_{q} Q_{t}$, for undrained and drained soils, may be selected with a certain degree of subjectivity, and several undrained/drained points occur in opposite sites. A uniform and relatively simple curve including an arc, parabola, or ellipse correlation can be more suitable and accessible. A database in the Yangtze Delta region has been collated to assess the three curves compared with the bilinear line. On the basis of abundant analyses executed in this study, the following conclusions can be obtained:

Regarding RMSE, the bilinear curve $(\mathrm{RMSE}=1.234)$ gave the best prediction unexpectedly. For the general overestimation $(K>1$ or $\mathrm{RE}>0)$ of $B_{q} Q_{t}$, all four curves had below $50 \%$ of the $K$ values greater than 1 . In terms of accuracy, $\mathrm{SD}, \mathrm{RD}$, and $\mathrm{RI}$, the arc, parabola, and ellipse curves that ignored distinction of the undrained and drained soils and took out the intersecting line could provide expressions for simplification and gave better performance than the bilinear line. Considering the consistency of measured and predicted $B_{q} Q_{t}$ values, the overall best curve was the ellipse $(\mathrm{RD}=0.580)$ with two variables. This is expected to improve the application scope and simplicity.

\section{Data Availability}

Data supporting the results of my study were generated during the study.

\section{Conflicts of Interest}

The authors declare no conflict of interest.

\section{Authors' Contributions}

Mingfei Zhang provided the main ideas and data processing of the whole paper. Liyuan Tong did the experiments and provided guidance for ideas and data processing.

\section{Acknowledgments}

The financial support from the National Natural Science Foundation of China (Grant Nos. 41902266 and 51878157) and Key R\&D and Promotion Projects in Henan Province (tackling key problems in science and technology) (Grant Nos. 212102310275, 202102310240, 202102310572, 212102310967, and 212102310968) are gratefully acknowledged.

\section{References}

[1] O. Sivrikaya and E. Togrol, "Determination of undrained strength of fine-grained soils by means of SPT and its application in Turkey," Engineering Geology, vol. 86, no. 1, pp. 52-69, 2006.

[2] S. Onyejekwe, X. Kang, and L. Ge, "Assessment of empirical equations for the compression index of fine-grained soils in Missouri," Bulletin of Earthquake Engineering, vol. 74, pp. 705-716, 2015.

[3] H. Güllü, H. Canakci, and A. Alhashemy, "Use of ranking measure for performance assessment of correlations for the compression index," European Journal of Environmental and Civil Engineering, vol. 22, no. 5, pp. 578-595, 2016.

[4] H. Güllü, H. Canakci, and A. Alhashemy, "A ranking distance analysis for performance assessment of UCS versus SPT-N correlations," Arabian Journal for Science and Engineering, vol. 44, no. 5, pp. 4325-4337, 2019.

[5] T. Lunne, P. Robertson, and J. Powell, "Cone penetration testing in geotechnical practice," CRC Press, London, 2002.

[6] P. Robertson, "Soil classification using the cone penetration test," Canadian Geotechnical Journal, vol. 27, no. 1, pp. 151158, 1990.

[7] G. J. Cai, Study on Theory and Engineering Application of Digital Multifunctional Piezocone Penetration Test (CPTU), Southeast University, Nanjing, 2010. 
[8] Q. Lu, M. Randolph, Y. Hu, and C. Bugarski, "A numerical study of cone penetration in clay," Géotechnique, vol. 54, no. 4, pp. 257-267, 2004.

[9] J. P. Wang, Y. S. Xu, L. Ma, and S. L. Shen, "An approach to evaluate hydraulic conductivity of soil based on CPTU test," Marine Georesources \& Geotechnology, vol. 31, no. 3, pp. 242-253, 2013.

[10] S. E. Burns and P. W. Mayne, "Monotonic and dilatory porepressure decay during piezocone tests in clay," Canadian Geotechnical Journal, vol. 35, no. 6, pp. 1063-1073, 1998.

[11] P. K. Robertson, J. P. Sully, D. J. Woeller, T. Lunne, J. J. Powell, and D. G. Gillesp, "Estimating coefficient of consolidation from piezocone tests," Canadian Geotechnical Journal, vol. 29, no. 4, pp. 539-550, 1992.

[12] P. Robertson, "Estimating in-situ soil permeability from CPT \& CPTU," Canadian Geotechnical Journal, vol. 46, no. 1, pp. 442-447, 2009.

[13] M. Jefferies and M. Davies, "Use of CPTU to estimate equivalent SPT N60," Geotechnical Testing Journal, vol. 16, no. 4, pp. 458-468, 1993.

[14] D. Elsworth and D. Lee, "Permeability determination from on-the-fly piezocone sounding," Journal of Geotechnical and Geoenvironmental Engineering, vol. 131, no. 5, pp. 643-653, 2005.

[15] D. Elsworth and D. Lee, "Limits in determining permeability from on-the-fly uCPT sounding," Géotechnique, vol. 57, no. 8, pp. 679-685, 2007.

[16] J. Chai, P. Agung, T. Hino, Y. Igaya, and J. P. Carter, "Estimating hydraulic conductivity from piezocone soundings," Géotechnique, vol. 61, no. 8, pp. 699-708, 2011.

[17] H. F. Zou, G. J. Cai, and S. Y. Liu, "Evaluation of coefficient of permeability of saturated soils based on CPTU dislocation theory," Chinese Journal of Geotechnical Engineering, vol. 36, no. 3, pp. 519-528, 2014.

[18] S. L. Shen, J. P. Wang, H. N. Wu, Y. S. Xu, G. L. Ye, and Z. Y. Yin, "Evaluation of hydraulic conductivity for both marine and deltaic deposits based on piezocone testing," Ocean Engineering, vol. 110, pp. 174-182, 2015.

[19] C. Wroth, "The interpretation of in situ soil tests," Géotechnique, vol. 34, no. 4, pp. 449-489, 1984.

[20] J. Briaud and L. Tucker, "Measured and predicted axial response of 98 piles," Journal of Geotechnical Engineering, vol. 114, no. 9, pp. 984-1001, 1988.

[21] C. Cherubini and C. Giasi, "Correlation equations for normal consolidated clays," Coastal Geotechnical Engineering in Practice, vol. 1, pp. 15-20, 2000.

[22] C. Giasi, C. Cherubini, and F. Paccapelo, "Evaluation of compression index of remoulded clays by means of Atterberg limits," Bulletin of Engineering Geology and the Environment, vol. 62, no. 4, pp. 333-340, 2003.

[23] M. F. Zhang, L. Y. Tong, Y. J. Yang, H. N. Che, and H. S. Pan, "In situ determination of hydraulic conductivity in Yangtze Delta deposits using a modified piezocone model," Bulletin of Engineering Geology and the Environment, vol. 77, no. 1, pp. 153-164, 2018.

[24] M. F. Zhang and L. Y. Tong, "New statistical and graphical assessment of CPT-based empirical correlations for the shear wave velocity of soils," Engineering Geology, vol. 226, pp. 184-191, 2017.

[25] Y. G. Zhang, J. Tang, R. P. Liao et al., "Application of an enhanced BP neural network model with water cycle algo- rithm on landslide prediction," Stochastic Environmental Research and Risk Assessment, 2020.

[26] Y. G. Zhang, J. Tang, Z. Y. He, J. K. Tan, and C. Li, “A novel displacement prediction method using gated recurrent unit model with time series analysis in the Erdaohe landslide," Natural Hazards, vol. 105, no. 1, pp. 783-813, 2021.

[27] Y. G. Zhang and L. N. Yang, "A novel dynamic predictive method of water inrush from coal floor based on gated recurrent unit model," Natural Hazards, vol. 105, no. 2, pp. $2027-$ 2043, 2021.

[28] Y. G. Zhang, Z. Zhang, and S. Xue, "Stability analysis of a typical landslide mass in the Three Gorges Reservoir under varying reservoir water levels," Environmental Earth Sciences, vol. 79, no. 1, 2020.

[29] Y. G. Zhang, S. Y. Zhu, J. K. Tan, L. D. Li, and X. J. Yin, "The influence of water level fluctuation on the stability of landslide in the Three Gorges Reservoir," Arabian Journal of Geosciences, vol. 13, no. 17, p. 845, 2020.

[30] Y. G. Zhang, S. Y. Zhu, W. Q. Zhang, and H. Liu, "Analysis of deformation characteristics and stability mechanisms of typical landslide mass based on the field monitoring in the Three Gorges Reservoir, China," Journal of Earth System Science, vol. 128 , no. 1,2019

[31] B. Gong, Y. J. Jiang, P. Yan, and S. Zhang, "Discrete element numerical simulation of mechanical properties of methane hydrate-bearing specimen considering deposit angles," Journal of Natural Gas Science and Engineering, vol. 76, article 103182, 2020.

[32] B. Gong, Y. J. Jiang, and L. J. Chen, "Feasibility investigation of the mechanical behavior of methane hydrate- bearing specimens using the multiple failure method," Journal of Natural Gas Science and Engineering, vol. 69, article 102915, 2019. 